\title{
Comparison of fetal outcome in spontaneous versus induced labor in postdated pregnancy: a study in a tertiary care centre
}

\author{
Nikhil Anand, Hardik Shah* \\ Department of Obstetrics and Gynaecology, Gujarat Medical Education and Research Society and Sola Civil Hospital, \\ Sarkhej-Gandhinagar Highway, Sola, Ahmedabad, Gujarat, India
}

Received: 26 July 2018

Accepted: 28 August 2018

\section{*Correspondence:}

Dr. Hardik Shah,

E-mail: hdshah1989@yahoo.com

Copyright: ( $\odot$ the author(s), publisher and licensee Medip Academy. This is an open-access article distributed under the terms of the Creative Commons Attribution Non-Commercial License, which permits unrestricted non-commercial use, distribution, and reproduction in any medium, provided the original work is properly cited.

\begin{abstract}
Background: Pregnancy lasting beyond 40 weeks is a known complication of normal delivery. Various studies have found incidence between $2-14 \%$. Post-dated pregnancy carries specific hazards to both mother and fetus. While mothers are faced with problems like increased incidences of induced labour, instrumental delivery and LSCS with associated morbidities, fetuses are faced with morbidities ranging from IUGR to macrosomia. Authors tried to study fetal outcome in post-dated pregnancy present study. The objective is to compare fetal outcome in spontaneous versus induced labour in post-dated pregnancy.

Methods: This is a prospective cross-sectional study done at a tertiary care hospital in obstetrics and gynecology in duration of 18 months. After screening according to inclusion criteria, all patients who were admitted in labour wards are selected and two groups were created according to clinical examination. First group consists of patients with spontaneous onset of labour and second group consists of patients with induction of labour. In each group USG, NST and BPP were performed, and labor monitored according to standard partograph. Fetal outcomes in both groups were studied.

Results: Fetal outcomes were nearly same in both groups, induced and spontaneous onset of labour, except a few like thick meconium which was common in spontaneous onset group while rate of LSCS was more in induced group.

Conclusions: Women with uncomplicated pregnancies should be offered induction of labour, while women with any complicating factors LSCS should be considered.
\end{abstract}

Keywords: Induction, LSCS, Neonatal morbidity, Postdatism

\section{INTRODUCTION}

Postdate, post term, post maturity, and prolonged pregnancy is accepted terms by WHO and the International Federation of Gynecology and Obstetrics to describe pregnancy beyond dates (expected date of delivery). Postdate pregnancy is defined as a pregnancy that had passed 40 completed weeks WHO and FIGO defined post term pregnancy as a pregnancy with a gestational length of 294 days or more. ${ }^{1,2}$ Prolongation of pregnancy complicates up to $10 \%$ of all pregnancies and carries increased risk to mother and fetus. ${ }^{3,4}$ Estimation of gestational age is the foundation for diagnosis and subsequent management of postdated pregnancy. Primary method is by dating by LMP, with naegles rule according to which incidence of labor at or after 42 weeks is $14 \% .^{5}$

Post term perinatal mortality is greater than that of term pregnancy in almost all studies reviewed. ${ }^{6}$ Prolonged pregnancy has always been regarded as a high-risk condition because perinatal morbidity and mortality is known to rise. ${ }^{7}$ Postdate pregnancy increase the risk of 
stillbirth and neonatal death. At or after 41 weeks there is increased incidence of decrease in liquor. ${ }^{8}$ Meconium passage in liquor also increases with postdate pregnancy and incidences range from $12 \%$ to as high as $30-40 \%{ }^{9}$ MAS (meconium aspiration syndrome) is associated with low Apgar scores and high fetal morbidity and mortality. ${ }^{10,11}$ Fetal macrosomia is also a known complication of postdated pregnancy which can lead to increased maternal and fetal trauma shoulder dystocia with resulting Erb's palsy, perinatal asphyxia, meconium aspiration and post-partum haemorrhage. ${ }^{12}$

Several studies have reported increased stillbirth rate from 41 weeks gestation and some have reported increased risk from 40 weeks gestation. ${ }^{13,14}$ The reported prevalence of postdate pregnancies vary between $5.5 \%$ and $9.5 \%$ in different studies countries and time period. ${ }^{14}$

As there is fetal and maternal risk associated with postdated pregnancy, need of induction is more with postdated pregnancy. There are several recommendations for the postdate pregnancy management, but no protocol is considered as gold standard, so management varies from hospital to hospital and country to country.

The aim of the present study was to do analytic comparison of the fetal outcome in spontaneous versus induced labour of pregnancies which crossed the expected date of delivery.

\section{METHODS}

This is a prospective cross-sectional study carried out in a tertiary care hospital for duration of 18 months. Patients who attended ANC OPD and patients admitted in labor wards were included after screening through inclusion criteria.

\section{Inclusion criteria}

- Sure, of dates.

- Who crossed the expected date of delivery by USG or LMP.

- $\quad$ Singleton pregnancy.

- Cephalic presentation.

- One first or second trimester USG.

- Unscarred uterus.

Total patients selected were 170 and divided under group 1 and group 2 according to the clinical examinations (mainly per vaginal and bishops score) of the patient.

Group 1 (spontaneous group) 85 patients with favorable bishops score.

Group 2 (induction group) 85 patients with unfavorable bishops score.

After assessment of bishops score every patient was studied in the respective group. On admission, ultrasound examination, nonstress test and biophysical profile test was done. In group 1 with good bishop score, patients were allowed spontaneous labour and labour monitored as per who criteria according to partograph.

In group 2 with low bishop score induction of labour done with intravaginal instillation of dinoprostone gel in posterior fornix with proper aseptic precautions after taking informed consent and excluding hypersensitivity. After 6 hours vaginal examination was repeated, if cervix was favorable than oxytocin augmentation done and if not favorable than repeat induction done with dinoprostone gel taking all precautions. After 6 hours again examination done, if cervix was found favorable than oxytocin augmentation done and if not favorable than LSCS done for failed induction.

In both groups labor abnormalities were identified by Freidman's criteria using partograph. Labor augmentation was done with amniotomy at $4-5 \mathrm{~cm}$ dilation and oxytocin as per need. If liquor was not clear (meconium stained) decision of LSCS taken as per FHR monitoring in both groups. According to mode of delivery maternal and fetal outcome were studied.

\section{RESULTS}

Table 1 shows that when gestational age was calculated by first ultrasound, $42.35 \%$ cases were $<41$ weeks and $56.47 \%$ were between $41-41$ w6d. while only $1.17 \%$ were at or beyond 42 weeks.

Similarly, when GA was calculated by dates (LMP) $36.47 \%$ were $<41$ weeks and $50.58 \%$ were between 41 41 w6d while $12.94 \%$ were at or beyond 42 weeks.

Table 1: Distribution of cases according to gestational age.

\begin{tabular}{|lll|}
\hline Gestational age & By dates & By USG \\
\hline No. $(\%)$ & No. $(\%)$ \\
\hline $41-40$ w 6 d & $62(36.47)$ & $72(42.35)$ \\
\hline 42 and $>42$ & $86(50.58)$ & $96(56.47)$ \\
\hline Total & $22(12.94)$ & $2(1.17)$ \\
\hline Mean \pm SD & $41.18 \pm 0.85$ & $170(100)$ \\
\hline
\end{tabular}

Table 2 shows that out of 170 pts $80 \%$ were having AFI more than 5 and $20 \%$ were having AFI 5 or less. NST was not applicable in 10 diagnosed IUD patients.in rest NST was reactive in $92.5 \%$ cases while non-reactive in $7.5 \%$ cases.

BPP was done in group 2 patients of whom 3 were IUD so $n$ was 82 out of them $92.68 \%$ had normal BPP while $7.31 \%$ had abnormal BPP.

Table 3 shows that in both the group majority patients were having clear liquor (nearly $70 \%$ ), while in group 1 
$8.23 \%$ patients had thick meconium and $8.23 \%$ had dark brown colored meconium.

In comparison in group $26.47 \%$ patients had thick meconium and $5.88 \%$ had dark brown colored meconium.

Table 4 shows that majority of patients were delivered vaginally in both the groups. In group $171.76 \%$ were vaginally delivered while $2.35 \%$ needed instrumental deliveries and $25.88 \%$ needed LSCS.

Similarly, in group $265.88 \%$ were vaginally delivered while $3.52 \%$ needed instrumental deliveries and $30.58 \%$ needed LSCS.
Table 2: Distribution of cases according to fetal surveillance test.

\begin{tabular}{|lll|}
\hline Fetal surveillance test & Number & Percentage \\
\hline AFI & & \\
\hline$>5$ & 136 & 80 \\
\hline$\leq 5$ & 34 & 20 \\
\hline Total & 170 & 100 \\
\hline Non-stress test & & \\
\hline Reactive & 148 & 92.5 \\
\hline Non-reactive & 12 & 7.5 \\
\hline Total & 160 & 100 \\
\hline Biophysical profile & & \\
\hline Normal & 76 & 92.68 \\
\hline Abnormal & 6 & 7.31 \\
\hline Total & 82 & 100 \\
\hline
\end{tabular}

Table 3: Distribution of cases according to color of liquor.

\begin{tabular}{|lllllll|}
\hline Color of liquor & Group 1 & & Group 2 & & Total \\
\hline Clear & No. & Percent & No. & Percent & No. & Percent \\
\hline Meconium & 39 & 69.41 & 61 & 71.76 & 120 & 70.58 \\
\hline Tinged/stained & & & & & & \\
\hline Thick & 12 & 14.11 & 17 & 19.99 & 29 & 17.05 \\
\hline Dark Brown & 7 & 8.23 & 4 & 4.70 & 11 & 6.47 \\
\hline Total & 7 & 8.23 & 3 & 3.52 & 10 & 5.88 \\
\hline
\end{tabular}

Table 4: Distribution of cases according to mode of delivery.

\begin{tabular}{|lllllll|}
\hline Mode of delivery & Group 1 & & Group 2 & & Total & Percent \\
\hline Vaginal & No. & Percent & No. & Percent & No. & 68.82 \\
\hline Instrumental & 61 & 71.76 & 56 & 65.88 & 117 & 2.94 \\
\hline LSCS & 2 & 2.35 & 3 & 3.52 & 5 & 28.23 \\
\hline Total & 22 & 25.88 & 26 & 30.58 & 48 & 100 \\
\hline
\end{tabular}

Table 5 shows that majority of babies were having birth weight between $2.5-3 \mathrm{~kg}$. While in group $124.70 \%$ babies were $<2.5 \mathrm{~kg}, 60 \%$ were between 2.5 to $3 \mathrm{~kg}$ and
$15.29 \%$ were $3 \mathrm{~kg}$ or more. the figures for group 2 were $21.17 \%$ babies were $<2.5 \mathrm{~kg}, 61.17 \%$ were between 2.5 to $3 \mathrm{~kg}$ and $17.64 \%$ were $3 \mathrm{~kg}$ or more.

Table 5: Distribution of cases according to fetal birthweight.

\begin{tabular}{|lllllll|}
\hline Out come & Group 1 & & Group 2 & & Total & \\
\hline Birth weight $(\mathbf{g m})$ & No. & \% & No. & \% & No. & \% \\
\hline $2000-2499$ & 21 & 24.70 & 18 & 21.17 & 39 & 22.94 \\
\hline $2500-2999$ & 51 & 60 & 52 & 61.17 & 103 & 60.58 \\
\hline 3000 and more & 13 & 15.29 & 15 & 17.64 & 28 & 16.47 \\
\hline Total & 85 & 100 & 85 & 100 & 170 & 100 \\
\hline Mean \pm SD & $2.42 \pm 0.45$ & & & & & \\
\hline
\end{tabular}


Table 6 shows that while in group $19.09 \%$ patients had Apgar score below 7 and 90.99 had score above 7, same data for group 2 showed $6.09 \%$ had score below 7 and $93.90 \%$ had score above 7. Difference between the group was found to be non-significant according to $\mathrm{p}$ value.

Table 6: Distribution of cases according to APGAR score.

\begin{tabular}{|c|c|c|c|c|c|c|c|}
\hline \multirow{2}{*}{ Apgar score at $5 \mathrm{~min}$. } & \multicolumn{2}{|c|}{ Group 1} & \multicolumn{2}{|c|}{ Group 2} & \multicolumn{2}{|c|}{ Total } & \multirow[b]{2}{*}{$P$ value } \\
\hline & No. & $\%$ & No. & $\%$ & No. & $\%$ & \\
\hline$<7$ & 7 & 9.09 & 5 & 6.09 & 12 & 7.54 & 0.564 \\
\hline$>7$ & 70 & 90.99 & 77 & 93.90 & 147 & 92.45 & 0.564 \\
\hline total & 77 & 100 & 82 & 100 & 159 & 100 & \\
\hline
\end{tabular}

Table 7: Distribution of cases according to neonatal morbidity.

\begin{tabular}{|llllllll|}
\hline Neonatal morbidity & Group 1 & \multicolumn{9}{c}{ Group2 } & \multicolumn{3}{c|}{ Total } & P value \\
\hline Asphyxia & No. & \% & No. & \% & No. & \% & 0.739 \\
\hline MAS & 5 & 35.71 & 4 & 30.76 & 9 & 33.33 & 0.414 \\
\hline RDS & 4 & 28.57 & 2 & 15.38 & 6 & 22.22 & 0.705 \\
\hline Others & 3 & 21.42 & 4 & 30.76 & 7 & 25.92 & 0.655 \\
\hline Total & 2 & 14.28 & 3 & 23.07 & 5 & 18.51 & 100 \\
\hline
\end{tabular}

Table 7 shows distribution of cases according to neonatal morbidity, which is on lower side in current study. In group 114 babies while in group 213 babies suffered morbidity there was no mortality in present study. When in group 1 others morbidity include hyperbilirubinemia, septicemia, pneumonia. There was no statistical significance in both groups.

\section{DISCUSSION}

The study was done in tertiary care hospital in obstetrics and gynecology department. The study duration was 18 months.170 patients who were past their expected date of delivery were studied after screening by inclusion criteria. In present study according to gestational age by dates, majority of cases were between 41-42 weeks of gestation accounting $50.58 \%$, while only $12.94 \%$ cases were more than 42 weeks. When gestational age was calculated by first ultrasound, majority of cases were between 41-42 weeks and only $1.17 \%$ were $>42$ weeks which corroborates with Aleaxander $\mathrm{J}$ et al. ${ }^{15}$

NST was reactive in majority. Similar results were found with Miller et al, Vintzilous et al, Eden et al. ${ }^{16-18} 10$ patients were diagnosed as IUFD in the present study.

BPP was done in group 2 patients and authors found abnormal BPP in $7.3 \%$, Eden et al, Miller et al advocated $7.9 \%$ and $9.9 \%$ abnormal BPP in their studies respectively. ${ }^{16,18}$ Chances of thick meconium are more in group1 than in group 2. Majority of patient were having clear liquor $(70.6 \%)$ which collaborates with findings of with Aleaxander $\mathrm{J}$ et al who had found $75.4 \%$ incidence of clear liquor. ${ }^{15}$
Number of instrumental deliveries and LSCS was more in group 2 but it was not statistically significant. Majority of babies were having APGAR score $>7$ (92.45\%) Aleaxander $\mathrm{J}$ et al had also found similar results. ${ }^{15}$

Out of 170, $14(16.47 \%)$ in group 1 and $13(15.29 \%)$ in group 2 were having neonatal morbidity. It was not statistical significance. Singal P et al quoted similar result in their study. ${ }^{19}$

\section{CONCLUSION}

Post datism still remains a controversial clinical entity. Regular ANC is important because of definite risk to the fetus if pregnancy continues beyond 40 weeks of gestation. It is associated with increased perinatal morbidity and mortality especially for those patients who don't take regular antenatal visits. Confirmation of diagnosis of postdatism is very important as many patients don't remember LMP and not having regular cycles. Diagnosis should be confirmed by first trimester USG which is most important non-invasive method and readily available in all hospitals. Fetal surveillance methods like NST, AFI, and BPP help in intensive and vigilant monitoring of fetuses. This helps in decreasing the perinatal morbidity and mortality in postdated pregnancy and achieving a favorable outcome.

After 41 weeks of gestation if the dates are confirmed women should be offered elective delivery. Women with uncomplicated pregnancies should be offered induction of labour, while women with any complicating factors LSCS should be considered. 
Funding: No funding sources

Conflict of interest: None declared

Ethical approval: Not required

\section{REFERENCES}

1. WHO: recommended definitions, terminology and format for statistical tables related to the perinatal period and use of a new certificate for cause of perinatal deaths. Modifications recommended by FIGO as amended October 14, 1976. Acta Obstet Gynecol Scand. 1977;56(3):247-53.

2. FIGO. Report of The FIGO Subcommittee On Perinatal Epidemiology And Health Statistics. London: FIGO; 1986.

3. Olesen AW, Westergaard JG, Olsen J. Perinatal and maternal complications related to post term delivery: a national register-based study, 1978-1993. Am J Obstet Gynecol. 2003;189:222-7.

4. Norwitz ER, Snegovskikh VV, Caughey AB. Prolonged pregnancy: when should we intervene? Clin Obstet Gynecol. 2007;50:547-57.

5. Manning FA, Platt LD, Sips L, Keegan KA. Fetal breathing movements and non stress test in high risk pregnancies. Am J obstet Gynaecol. 1979;135:511-5.

6. Vorherr H. Placental insufficiency in relation to postterm pregnancy and fetal postmaturity: Evaluation of fetoplacental function; management of the postterm gravida. Am J Obstetr Gynecol. 1975;123(1):67-103.

7. Grant JM. Induction of labour confers benefits in prolonged pregnancy. $\mathrm{Br} \mathrm{J}$ Obstet Gynaecol. 1994;101:99-102.

8. Divon MY, Haglund B, Nisell H, Otterblad PO. Fetal and neonatal mortality in postterm pregnancy: the impact of gestational age and fetal growth restriction. Am J Obstet Gynecol. 1998;178(4):726-31.

9. Ahanya SN, Lakshmanan J, Morgan BL, Ross MG. Meconium passage in utero: mechanisms, consequences, and management. Obstet Gynecol Survey. 2005;60(1):45-56.

10. Starks GC. Correlation of meconium stained amniotic fluid, early intrapartum fetal $\mathrm{pH}$ and Apgar scores as predictors of perinatal outcome. Obstet Gynecol. 1980;56(5):604-9.
11. Krebs HB, Peters RE, Dunn LJ. Intrapartum fetal heart rate monitoring. Association of meconium with abnormal fetal heart rate patterns. Am J Obstet Gynecol. 1980;137:936-43.

12. Weiner Z, Farmakides G, Schulman H, Casale A, Iskovitz-Eldor J. Central and peripheral haemodynamic changes in post term fetuses: correlation with oligohydramnios and abnormal fetal heart rate pattern. $\mathrm{Br} \mathrm{J}$ Obstet Gynaecol. 1996;103(6):541-6.

13. Pandis GK, Papageorghiou AT, Ramanathan VG, Thompson MO, Nicolaides KH. Pre-induction sonographic measurement of cervical length in the prediction of successful induction of labor. Ultrasound Obstet Gynecol. 2001;18(6):623-8.

14. Pattison N, McCowqn L. Cardiotocography for antepartum fetal assessment. The Cochrane Database Syst Rev. 2000;2:CD001068.

15. Macer JA, Macer CL, Chan LS. Elective induction versus spontaneous labor: a retrospective study of complications and outcome. Am J Obstet Gynecol. 1992;166(6):1690-7.

16. David AM, Yolando A, Rabello, Richard HP. The MBPP: antepartum testing in 1990s. Am J Obstet Gynaecol. 1996;174:812-7.

17. Vintzileous AM, Campbell WA, Ingardie CJ, Nochimson DJ. The foetal BPP and it predictive value. Obstet Gynaecol. 1983;62:217-8.

18. Eden RD, Sifert LS, Kodack LD, et al. A MBPP for antenatal fetal surveillance. Obstet Gynecol. 1988;71(3):365-9.

19. Singal P, Anjana S, Deepali J, Vishal P. Fetomaternal outcome following postdate pregnancya prospective study. $\mathrm{J}$ Obstet Gynecol Ind. 2001;51(5):89-93.

Cite this article as: Anand N, Shah H. Comparison of fetal outcome in spontaneous versus induced labor in postdated pregnancy: a study in a tertiary care centre. Int J Reprod Contracept Obstet Gynecol 2018;7:4081-5. 